\title{
The Use of Maintenance Electroconvulsive Therapy for Relapsing Depression
}

\author{
Ted A. Matzen, MD \\ University of Kansas School of Medicine \\ Ronald L. Martin, MD \\ University of Kansas School of Medicine \\ Tim J. Watt, MD \\ State University of New York at Syracuse \\ Douglas K. Reilly, MD \\ University of Kansas School of Medicine
}

Follow this and additional works at: https://jdc.jefferson.edu/jeffjpsychiatry

Part of the Psychiatry Commons

Let us know how access to this document benefits you

\section{Recommended Citation}

Matzen, MD, Ted A.; Martin, MD, Ronald L.; Watt, MD, Tim J.; and Reilly, MD, Douglas K. (1988) "The Use of Maintenance Electroconvulsive Therapy for Relapsing Depression," Jefferson Journal of Psychiatry. Vol. 6 : Iss. 1 , Article 8.

DOI: https://doi.org/10.29046/JJP.006.1.006

Available at: https://jdc.jefferson.edu/jeffjpsychiatry/vol6/iss1/8

This Article is brought to you for free and open access by the Jefferson Digital Commons. The Jefferson Digital Commons is a service of Thomas Jefferson University's Center for Teaching and Learning (CTL). The Commons is a showcase for Jefferson books and journals, peer-reviewed scholarly publications, unique historical collections from the University archives, and teaching tools. The Jefferson Digital Commons allows researchers and interested readers anywhere in the world to learn about and keep up to date with Jefferson scholarship. This article has been accepted for inclusion in Jefferson Journal of Psychiatry by an authorized administrator of the Jefferson Digital Commons. For more information, please contact: JeffersonDigitalCommons@jefferson.edu. 


\title{
The Use of Maintenance Electroconvulsive Therapy for Relapsing Depression
}

\author{
Ted A. Matzen, M.D. \\ Ronald L. Martin, M.D. \\ Tim J. Watt, M.D. \\ Douglas K. Reilly, M.D.
}

\section{INTRODUCTION}

It is generally accepted that electroconvulsive therapy (ECT) is an effective treatment of major depressive episodes in patients with both unipolar and bipolar affective disorders (1). Yet, repeated relapse of depression occurs in some patients, even with vigorous maintenance therapy on antidepressant drugs (2-4). This often necessitates rehospitalization for ECT. In past decades, several authors suggested that periodic outpatient ECT was efficacious as a maintenance therapy (5-7). Recently, maintenance ECT was recommended by Fink (8), and Maletzky (9), but barely mentioned in two reviews $(10,11)$, and discouraged in another (12). However, a recent nationwide survey has disclosed that such therapy is widely practiced (13).

Maintenance ECT has been used for a number of depressive patients at our medical center. Generally, patients are selected on the basis of a history of a good antidepressant response to a course (usually 6-12 thrice-weekly treatments) of inpatient ECT, and the repeated failure of various drug regimens to prevent relapse despite dosages deemed adequate (14) or limited by unmanageable side effects. All patients are thoroughly worked up for neurological, endocrine, or other disorders which might contribute to resistance to treatment. Typically, patients receive ECT weekly for one month, every other week for two months, then monthly for three months. The frequency and duration of maintenance ECT are adjusted according to the clinical course. This regimen is followed provided that remission is sustained. The frequency is increased if depressive symptoms recur. Frequently, patients receive antidepressant and other psychotropic medications in conjunction with ECT.

The present report reviews some recent experience with maintenance ECT. First, records of all patients treated with outpatient ECT during a three

Dr. Matzen is a third year resident in psychiatry at the University of Kansas School of Medicine. Dr. Martin was the Director of Residency Training at the same institution, and is currently Professor and Chairman of the Department of Psychiatry at the University of Kansas School of Medicine, Wichita. Dr. Watt is a third year resident in neurosurgery at the State University of New York at Syracuse. Dr. Reilly was a fourth year resident in psychiatry at the University of Kansas School of Medicine when the study was begun. 
year period from 1982 through 1984 were reviewed. Those for whom maintenance ECT was used for at least six weeks were selected for study. Eight patients were so treated during this period. The current (1987) status of each patient and the intervening course of illness and treatment history were ascertained.

Since treatment was not prospectively standardized, but was individually tailored to clinical course, the frequency and duration of therapy varied. For ease of review, the cases are categorized according to the treatment utilized and the apparent effectiveness of maintenance ECT. In addition to consideration of the overall course of illness, the rate of rehospitalization for depression in the two years subsequent to the initiation of maintenance ECT was compared with the two years prior to initiation as a crude indication of effectiveness. By "effectiveness" we mean the nearly total remission of affective, melancholic, and psychotic symptoms. All psychiatric diagnoses were according to DSM-III criteria.

ECT was performed in the standard manner for our hospital with an eight hour fast, intramuscular glycopyrrolate 30 minutes prior to treatment, intravenous methohexital or etomidate anesthesia, and succinylcholine muscle relaxation. Patients were carefully monitored to insure that a generalized seizure of at least 30 seconds duration had occurred. All were outpatients and were discharged when their vital signs were stable and they could safely leave with a relative or a friend.

\section{SUMMARY OF CASES}

\section{Maintenance ECT on a Continued Maintenance Basis}

Case 1. Mr. A, a 73-year-old, has suffered recurrent episodes of melancholic depression as part of a unipolar affective disorder for the past 26 years. Episodes were characterized by anhedonia, anorexia, agitation, and excruciating feelings of guilt and always responded to inpatient ECT. Lithium at 600 to 900 $\mathrm{mg}$ daily for years (serum level 0.5 to $0.8 \mathrm{meq} / \mathrm{l}$ ), trazodone $150 \mathrm{mg}$ daily for two months in conjunction with lithium, $50 \mathrm{mg}$ of amitryptyline daily for two months (serum level $148 \mathrm{ng} / \mathrm{ml}$ ), and desipramine $150 \mathrm{mg}$ daily for one year all failed to prevent relapse. During the two years before maintenance ECT was instituted, he was admitted six times for depressive relapses, the frequency of hospitalization having increased to approximately every three months. Maintenance ECT was initiated after a successful course of inpatient ECT. He has been admitted twice for inpatient ECT during the two years since outpatient ECT was begun, with the reinstitution of maintenance ECT upon discharge. Both relapses occurred when the frequency of ECT had been reduced to every four weeks. Remission has now been sustained for eight months with ECT every three weeks with no concurrent pharmacotherapy. 
Case 2. Mrs. B, a 65-year-old, has a 26 year history of recurrent melancholic depression requiring multiple hospitalizations despite attempted maintenance with various antidepressant medications including trazodone to $400 \mathrm{mg}$ daily for nine weeks. In addition to striking dysphoria, symptoms included anorexia, diurnal mood variation, and psychomotor retardation. During the two years prior to initiation of maintenance ECT, she was hospitalized three times for depression which responded to inpatient ECT, but relapse occurred despite maintenance nortriptyline $50 \mathrm{mg}$ daily for two months, then one month at 100 $\mathrm{mg}$ daily. While receiving a course of $18 \mathrm{ECT}$ when last hospitalized, she became hypomanic and lithium therapy was instituted in consideration of possible bipolar rather than unipolar affective disorder. Along with maintenance lithium 600 to $900 \mathrm{mg}$ daily (serum levels of 0.6 to $1.0 \mathrm{meq} / \mathrm{l}$ ), she received six weekly outpatient ECT. ECT was discontinued without tapering according to the wishes of the family. She remained asymptomatic on lithium alone for nearly two years but is now readmitted for inpatient ECT.

Case 3. Mrs. C is a 72-year-old, hospitalized four times with unipolar psychotic depression during the two years prior to maintenance ECT. Noteworthy symptoms were marked weight loss, terminal insomnia, agitation, suicidal thoughts, and delusional guilt. Depression was not fully alleviated with lithium at 900 to $1200 \mathrm{mg}$ daily (serum levels of 0.7 to $0.9 \mathrm{meq} / \mathrm{l}$ ), nor with concurrent desipramine $100 \mathrm{mg}$ daily for three months. She improved somewhat while on $300 \mathrm{mg}$ trazodone daily. During the third admission, she was treated with eight ECT showing good response. She was discharged on trazodone 200 to $300 \mathrm{mg}$ daily, but relapsed within one month. She received 10 inpatient ECT with marked improvement and was discharged on desipramine $100 \mathrm{mg}$ and lithium $900 \mathrm{mg}$ daily. Outpatient ECT was administered weekly for two treatments, then every other week for two treatments, followed by eight monthly treatments. She has been free of major affective symptoms for two years and is now maintained on desipramine and lithium as above.

Case 4. Mr. D, a 76-year-old considered to have a unipolar affective disorder, suffered the first of a series of recurrent severe depressions with psychosis at age 60 . Each episode was characterized by anergia, poor social interaction, paranoid and somatic delusions, and pseudodementia. Various pharmacotherapeutic regimens were ineffective and numerous rehospitalizations occurred. Maintenance medications tried included $50 \mathrm{mg}$ maprotiline daily for one month, $900 \mathrm{mg}$ lithium for three months, amitriptyline $75 \mathrm{mg}$ at bedtime for six months, desipramine $50 \mathrm{mg}$ daily for one month, then $75 \mathrm{mg}$ for three weeks, followed by nortriptyline $50 \mathrm{mg}$ daily for three weeks and $75 \mathrm{mg}$ for one month; usually in combination with low dose thioridazine. A course of inpatient ECT was markedly effective at age 70 , but he was then returned to maintenance medication. He remained chronically symptomatic with depression but was not rehospitalized until age 74 . Remission was obtained with a course of 
ECT. Thereafter, maintenance was achieved with weekly outpatient ECT for two months, then every two weeks for two months. He has since (for one and a half years) remained in remission on nortriptyline 50 to $75 \mathrm{mg}$ daily and thioridazine $25 \mathrm{mg}$ twice daily.

\section{Maintenance ECT Discontinued Against Advice}

Case 5. Mrs. E is a 69-year-old with a 23 year history of unipolar affective disorder with multiple episodes of melancholic depression responsive to inpatient ECT. In addition to extreme dysphoria, she would report total anhedonia, insomnia, and intense exacerbation of her chronic back pain. Imipramine 50 $\mathrm{mg}$, protriptyline $10 \mathrm{mg}$, amoxapine $50 \mathrm{mg}$, trazodone $300 \mathrm{mg}$, and phenelzine $30 \mathrm{mg}$ daily, each failed to prolong remission for more than three months. During the two years before maintenance ECT was begun, the patient was hospitalized on six occasions for a course of nine inpatient ECT. Following the last of these episodes, maintenance ECT was administered weekly for two weeks, then every two weeks for three months. In response to increasing depressive symptoms the frequency of treatment was increased to thrice weekly for three weeks, and remission was obtained. However, she then refused further maintenance ECT, citing concern regarding possible "brain damage." No further antidepressant medication was prescribed, and relapse occurred six months later. Since discontinuation of maintenance ECT, she has been admitted twice for inpatient ECT. For the past year remission has been sustained with trazodone $250 \mathrm{mg}$ daily. No signs of cognitive impairment are evident.

Case 6. Miss $\mathrm{F}$ is a 33-year-old with a 10 year history of a bipolar affective disorder. Manic episodes have always responded to neuroleptics and lithium. However, depressive episodes, with consistent suicidal ideation, have been refractory to lithium at 900 to $1200 \mathrm{mg}$ daily (serum levels of 0.7 to $0.9 \mathrm{meq} / \mathrm{l}$ ) to concurrent desipramine $100 \mathrm{mg}$ daily for three months, and to treatment with concurrent tranylcypromine at 30 to $90 \mathrm{mg}$ daily for several months. During the two year period prior to maintenance ECT, she was hospitalized four times: three times for depression and once for mania. Inpatient ECT was necessary once during the year following initiation of a regimen of maintenance ECT (weekly, every two weeks, then monthly). She then moved out of state, where maintenance has been attempted with various pharmacotherapeutic regimens but not ECT. She has been hospitalized three times for depression since the discontinuation of maintenance ECT.

Case 7. Mrs. G, a 63-year-old, considered to have a bipolar affective disorder, was first hospitalized for mania at age 58. The mania responded well to lithium, and she remained in remission for two years. During the two year period prior to maintenance ECT she was admitted three times for psychotic depression, characterized by insomnia, anorexia, agitation, obsessive behavior, and paranoid delusions. Each time she responded to a course of 12 ECT without antidepressant medication. An outpatient trial of imipramine $150 \mathrm{mg}$ daily for 
one year did not prevent recurrence of depression. Weekly outpatient ECT alone provided adequate maintenance for two months. She began to miss scheduled treatments possibly due to inadequate therapy. She rapidly deteriorated and was readmitted, but ECT was refused. A combination of nortriptyline $75 \mathrm{mg}$ and thioridazine $75 \mathrm{mg}$ daily for six weeks was ineffective and she continued to refuse ECT. She was transferred to a psychiatric nursing home where she continues to be severely depressed. She refuses further ECT. The family does not wish to have the patient adjudicated for involuntary treatment.

\section{Maintenance ECT Discontinued by Intercurrent Illness and Death}

Case 8. Mrs. H, a 68-year-old considered to have a bipolar affective disorder, was initially diagnosed with "depressive psychosis" at age 27. Subsequently, four manic episodes were responsive to lithium. She also suffered from severe chronic obstructive lung disease. She was hospitalized four times for psychotic depression during the two years prior to maintenance ECT. Symptoms included anergia, anhedonia, insomnia, delusional guilt, and visual hallucinations. These episodes proved refractory to treatment with $150 \mathrm{mg}$ imipramine daily for three years (serum level 168 to $231 \mathrm{ng} / \mathrm{ml}$ ) and protriptyline $20 \mathrm{mg}$ daily for three months, each in conjunction with lithium, but then responded to inpatient ECT. She remained euthymic while receiving a course of 10 weekly outpatient ECT. Then a full depressive relapse occurred coincident with a pneumonia superimposed on her lung disease. She died before more frequent ECT could be reinstituted.

\section{DISCUSSION}

The cases reviewed illustrate how ECT can be used as part of a maintenance strategy in preventing relapse of depression in patients with major affective disorder. As a crude measure of effectiveness, 30 hospitalizations for depression occurred during the two years prior to initiation of ECT for the selected group of patients, compared with 10 hospitalizations during the two year post-maintenance ECT period. Actually, only three of the relapse hospitalizations occurred in patients being actively treated with maintenance ECT, the other seven occurred in those who either refused further ECT or were no longer in treatment at our clinic.

In our experience, different patients required different frequency and duration of treatment. Of eight patients, one appeared to require chronic maintenance therapy, while three were treated on a temporary basis and then remained in extended remission while not receiving maintenance ECT. The long-term use of ECT is not uniformly well-received, and three patients refused further maintenance ECT despite its apparent effectiveness. On the whole, families seemed to accept continued ECT quite well. The one death in our review did not appear in any way related to ECT. 
It should be noted that all patients studied had a history of profound depressive episodes, often with melancholic or psychotic features. Four of the eight suffered from bipolar disorders. Previous depressions in these patients were responsive to inpatient ECT, but were generally refractory to pharmacotherapy. Such factors may predict which patients may best benefit from maintenance ECT. However, extensive further research will be necessary to establish a definitive protocol for determining which patients would benefit most.

The current report must be viewed as tentative support for the efficacy of maintenance ECT. It is a summary of clinical experience rather than a rigorously designed experimental study. Maintenance ECT regimens were not standardized, but were determined by the judgment of a number of clinicians. The possible effectiveness of maintenance ECT cannot be isolated from the confounding effects of various concurrent psychotropic medications. Anecdotal reports must always be interpreted cautiously, but until more definitive studies are available, this report does suggest another strategy in managing certain difficult cases.

Given these limitations, clinicians are encouraged to consider maintenance ECT in certain affective disorder patients who frequently relapse despite maintenance with medication. Rather than a drastic measure, maintenance ECT is probably safer, less expensive, and less disruptive than unsuccessful maintenance with medication, relapse, and repeated rehospitalizations. Selection of a maintenance ECT strategy should not lead to unnecessary intensity of treatment. As with medications, the "dosage" of maintenance ECT can be adjusted relative to the recurrence of symptoms. It is expected that few patients will require maintenance ECT on a chronic basis, with a return to maintenance with medications in most.

\section{REFERENCES}

1. Rose RM, Burt RA, Clayton PJ, et al: Electroconvulsive therapy, consensus conference. JAMA 1985; 254:2103-2108

2. Davis JM: Overview: maintenance therapy in psychiatry. Am J Psychiatry 1976; 133:1-13

3. Spiker DG, Stein J, Rich CL: Delusional depression and electroconvulsive therapy: One year later. Convulsive Ther 1985; 1:167-172

4. Aronson T, Shukla S, Hoff A: Continuation therapy after ECT for delusional depression: A naturalistic study of prophylactic treatment and relapse. Convulsive Ther 1987; 3:251-259

5. Kerman EF: Electroshock therapy, with special reference to relapses and an effort to prevent them. J Nerv \& Ment Dis 1945; 102:213-242

6. Stevenson GH, Geoghegan JJ: Prophylactic electroshock. Am J Psychiatry 1951; 107:743-748

7. Karliner W, Wehrheim HK: Maintenance convulsive treatments. Am J Psychiatry $1965 ; 121: 1113-1115$ 
8. Fink M: Convulsive Therapy: Theory and Practice. New York, Raven Press, 1979, p 207

9. Maletzky BM: Multiple-Monitored Electroconvulsive Therapy. Boca Raton, CRC Press, 1981, pp 11-12

10. Weiner RD: The psychiatric use of electrically induced seizures. Am J Psychiatry 1979; 136:1507-1517

11. Kendell RE: The present status of electroconvulsive therapy. Br J Psychiatry 1981; 139:265-283

12. Perr IN: Liability and electroshock therapy. J Forensic Sci 1980; 25:508-513

13. Kramer BA: Maintenance ECT: A survey of practice. Convulsive Ther 1987; $3: 260-268$

14. Keller MB, Lavori PW, Klerman GL, et al: Low levels and lack of predictors of somatotherapy and psychotherapy received by depressed patients. Arch Gen Psychiatry $1986 ; 43: 458-466$ 